\title{
TESTING OF 10 MW MULTIBEAM KLYSTRONS FOR THE EUROPEAN X-RAY FEL AT DESY
}

\author{
V. Vogel, S. Choroba, T. Froelich, T. Grevsmuehl, F.- R. Kaiser, V. Katalev, I. Sokolov, H. Timm, \\ DESY, 22607 Hamburg, Germany \\ A. Cherepenko, BINP, 630090, Novosibirsk, Russia
}

\begin{abstract}
For the European XFEL project multi-beam klystrons, which can produce RF power of $10 \mathrm{MW}$, at an RF frequency of $1.3 \mathrm{GHz}, 1.5 \mathrm{~ms}$ pulse length and $10 \mathrm{~Hz}$ repetition rate, were chosen as RF power sources. So far we have three companies which produce this kind of new klystron. At DESY we installed a new test stand dedicated for testing this new type of RF power source. So far we have tested several tubes from Thales (TH1801), Toshiba (E3736) and CPI (VKL8301) in our test stand. In this paper we give an overview of the test facilities and we summarize the current test results of the L-band multi-beam klystrons (MBK).
\end{abstract}

\section{INTRODUCTION}

The RF system for the European XFEL will be consist of $27 \mathrm{RF}$ stations including 25 for main linac and 2 for injector. Each RF station will supply RF power for 4 cryomodules. For the nominal gradient of $23.6 \mathrm{MeV} / \mathrm{m}$ the RF station should produce power at least of 5.2MW nominal and up to $10 \mathrm{MW}$ maximum with pulse duration up to $1.38 \mathrm{~ms}$ and a repetition rate up to $30 \mathrm{~Hz}$. A RF station will be located in the tunnel and consist of a horizontal multi-beam klystron, high voltage pulse transformer, a RF power distribution system, low level RF system, auxiliary power supplies and an interlock system. Each RF station will be connecting to the pulsed power supply through up to $1.5 \mathrm{~km}$ long high voltage cables [1], [5].

\section{TEST STAND}

The test stand for testing vertical RF power sources for XFEL was built at DESY in 2005. The main parameters of DESY test stand are given in Table 1. The test stand consists of the following elements:

Table 1: Technical Specification of test stand

\begin{tabular}{|c|c|}
\hline Repetition Rate & $10 \mathrm{~Hz}$ ) \\
\hline Current & 135 A nominal,145A max \\
\hline Cathode Voltage & $118 \mathrm{kV}$ nominal; 130kV max \\
\hline Average power & $300 \mathrm{~kW}$ \\
\hline Pulse top Flatness & $1 \%$ \\
\hline Pulse width (RF) & 1.5 millisecond \\
\hline Pulse width (HV) & 1.75 millisecond \\
\hline
\end{tabular}

- An oil filled high-voltage pulse transformer with the section for the connection to the vertical klystron. In this section are established a high voltage filament transformer, high voltage divider for measure the cathode voltage, current measuring transformer and tube socket for the connection of klystron to the transformer $\mathrm{HV}$ output. The high-voltage transformer and transitional module were manufactured by company ABB. Highvoltage transformer has a transformation ratio of 1:12 and is capable to issue the high voltage pulse up to $130 \mathrm{kV}$ and current up to $145 \mathrm{~A}$ with the duration of the pulse of 1.75 milliseconds and a repetition rate up to $10 \mathrm{~Hz}$.

- A bouncer type of modulator which was produced by the company PPT. The modulator has a compact main capacity bank of $1.4 \mathrm{mF}$. This capacity can be charged up to $12 \mathrm{kV}$ by DC power supply. The main switch is from 7 IGCTs in series was produced by ABB

- RF distribution system are based on the WR650 waveguides and consists of four RF calorimetric matched loads produced by the company Ferrite SP, E and H band, dividers, directional couplers and light sensors. The distribution system can be filled with SF6 or other gases; the maximum pressure is up to 1 bar. Fig. 1 shows the side view of the test stand.

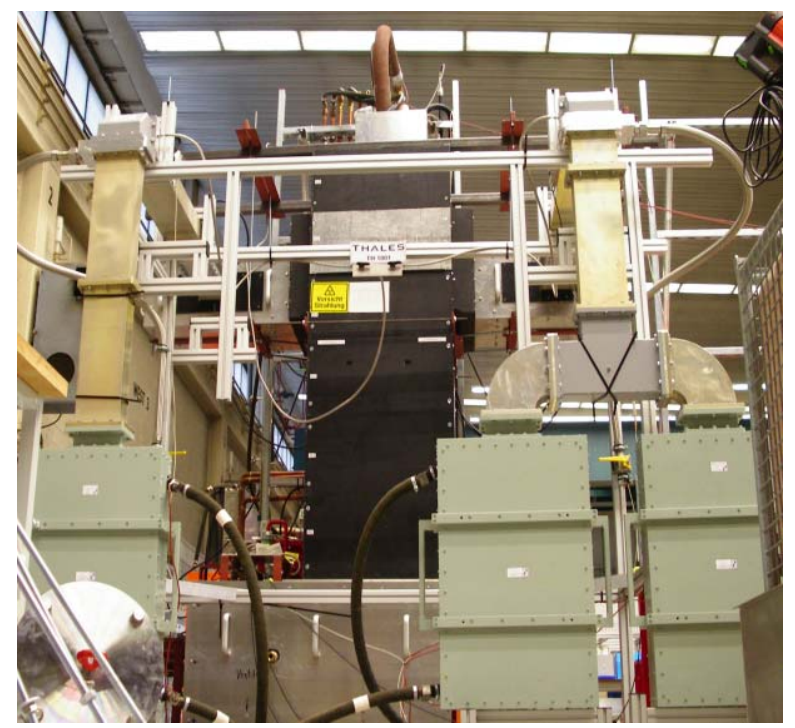

Figure 1: Test stand with MBK and waveguides system.

- Water cooling system which can give up to 320 litres per minute, including 250 litres for the collector. The water system has temperature and water flow sensors and 
has a heater to change the temperature of inlet water using for cooling the body of klystron.

- A low level RF system consists of a master oscillator, 650W peak preamplifier, fast RF switch and input output power and phase measurement system.

- A standard interlock system [2] is extended by a fast RF interlock based on the comparison of the predicted output RF waveforms and the real measured by crystal detectors. In case of differences between these two the interlock switches off the drive power to the klystron. This RF fast interlock is very useful during tube condition because it limits the power which comes to the discharge area inside the klystron and reduces the gas burst which can be source of klystron gun arcing. Typically the fast interlock switches off only few times during a run period of 100 hours when a klystron is fully conditioned.

- Measurement and data storage system is based on use the DAQ PC boards [6]. Measured channels are collected into the groups. All channels, which belong to one group, have common synchronization (external or internal) and are managed by dedicated server process. This process acquires data from DAQ PC board and makes them immediately available for clients over the network connection and also to store them on the network file system. The measuring system in addition to the standard voltage, current and temperature measurement can measure the level of X-ray too. We are using two different types of X-ray sensors. The first one is semiconductor sensor. The level of X-ray is proportional to the number of pulses from this sensor. The semi-conductor sensor is looking at the area of the output cavity of the klystron. Fig. 2 shows the waveform of the level of X-ray during condition of a klystron. Second ones is detector which consists of a plastic scintillation fibre and a photomultiplier [5]. This sensor is watching for the gun area of the klystron.

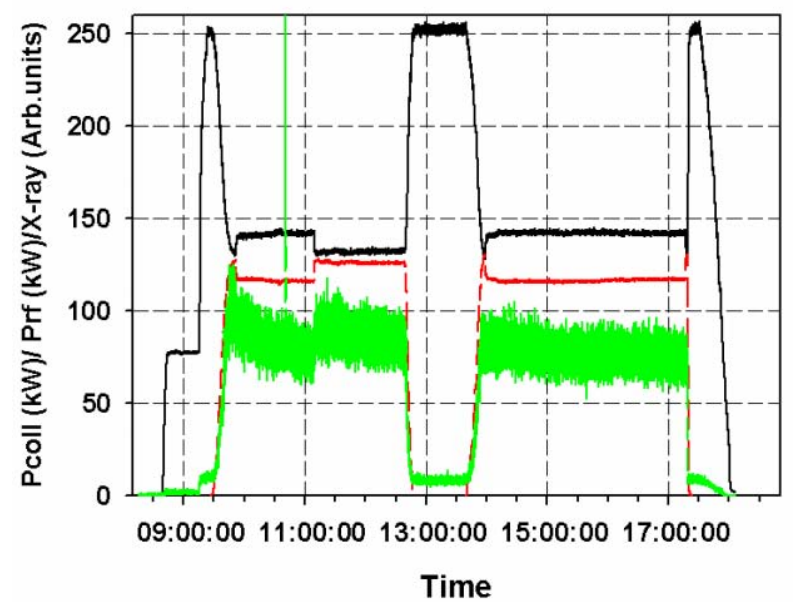

Figure 2: Level of X-ray from output cavity area, during the condition of klystron. Green line - X-ray level, black line- collector power, red line - RF output power.

\section{MBK'S TEST RESULT}

Since May 2005 at the DESY's test stand were measured 5 tubes from three companies. The three tubes from Thales [4], serial numbers \#1, \#3 and \#4 showed approximately equal results for maximum output power (10.1MW), efficiency (63\%), gain (48db), RF pulse length $(1.5 \mathrm{~ms})$, average RF power $(150 \mathrm{~kW})$ and repetition rate (10pps). Fig. 3 shows the output power as a function of beam voltage. Fig. 4 shows the bandwidth of tube \# 4 . The second test of tube \#1 which has been in operation about one and half year at DESY, Zeuthen does not show any signs of tube degradation.

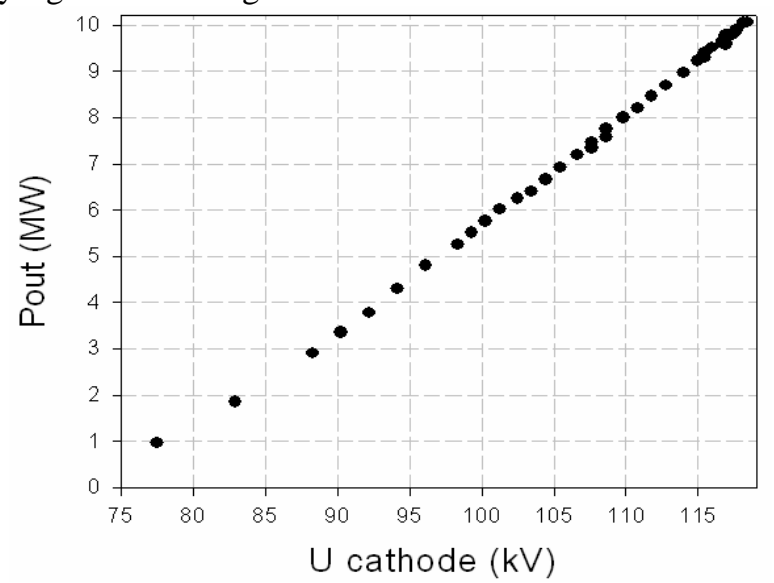

Figure 3: The output power in the saturation mode as a function of beam voltage, TH1801 SN\#4.

At present 6 tubes have been manufactured by Thales. Three tubes are in the operation, SN\#3 at FLASH since March 2006 total time of operation about 10600 hours, SN\#4 at PITZ since November 2006 and SN\#1 in the operation since May 2005 and in the test stand now. A prototype is in a reserve, total time of operation 20000 hours. SN\#5 is successfully tested at the factory and will be soon delivered into DESY.

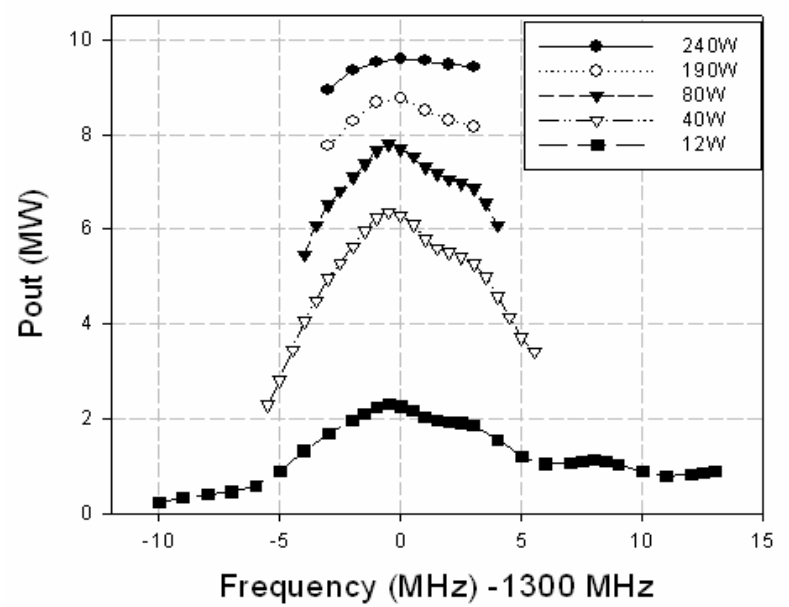

Figure 4: The bandwidth of TH1801 SN\#4.

In June 2006 we started the test the Toshiba MBK E3736 [3]. This tube had been fully conditioned at the factory and immediately after installation we got parameters exceeding the specification, the maximum output power $10.4 \mathrm{MW}$, efficiency $66 \%$ and gain $49 \mathrm{db}$ at a RF pulse length of $1.5 \mathrm{~ms}$ average RF power of $150 \mathrm{~kW}$ and repetition rate of 10 pps. Fig. 5 shows the output power as 
a function of beam voltage and Fig.6 shows the bandwidth of Toshiba E3736. During acceptance test this tube was operated 24 hours at full power without breakdown. Total time of the operation of E3736 at the DESY test stand is about 750 hours. Now the tube is kept at DESY for future use.

\section{Toshiba MBK (saturation mode)}

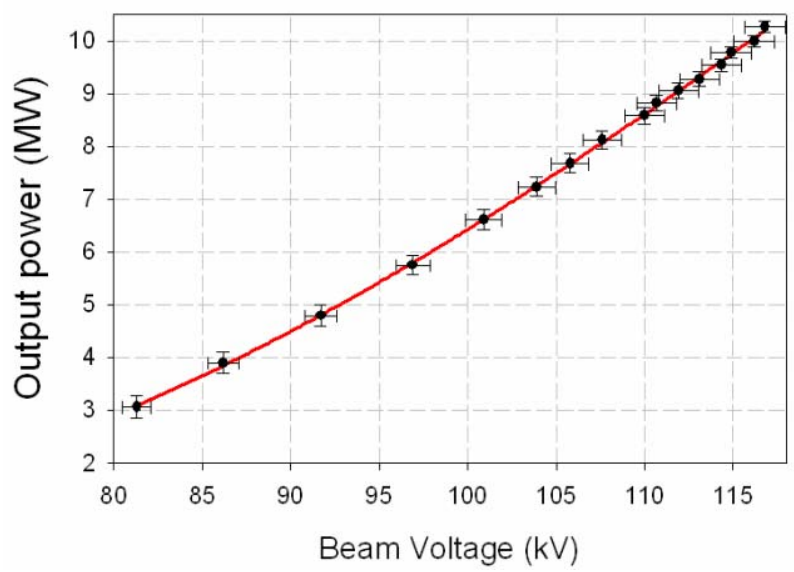

Figure 5: The output power in the saturation mode as a function of beam voltage, E3736.

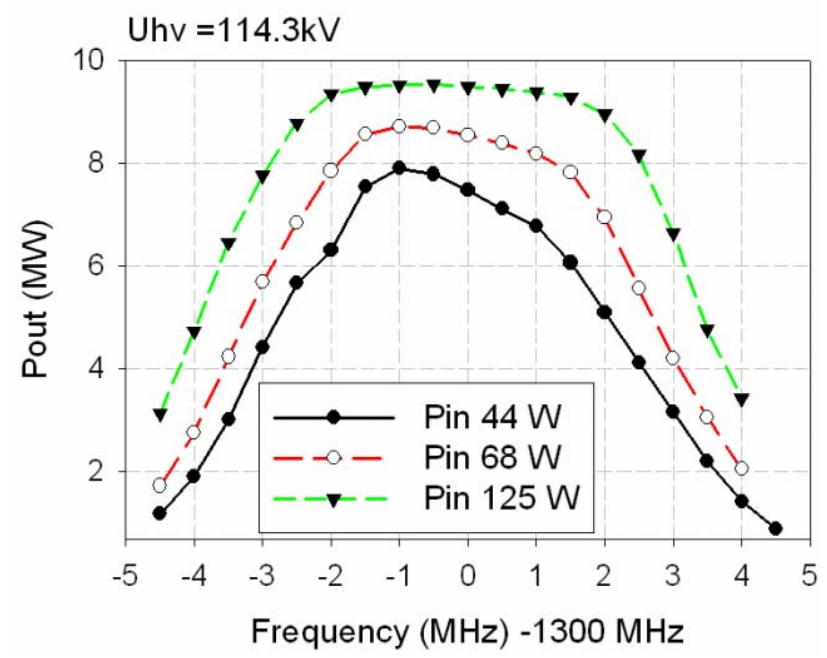

Figure 6: Bandwidth of E3736.

\section{PREPARATION FOR TESTING OF HORIZONTAL MBK}

For testing horizontal MBKs at DESY we have already started the reconstruction of our existing test stand. We are now investigating the connection of the horizontal MBK and the pulse transformer. The HV pulse transformer has weight of $6.5 \mathrm{t}$ and the horizontal MBK has whole weight of $3 \mathrm{t}$. We have three variants of this connection. The first - the support frame of MBK should have a precise alignment mechanism, the second - between HV pulse transformer and MBK we will use the bellows and the third - we can make this connection using a special connection module at the klystron side and $\mathrm{HV}$ cable between klystron and pulse transformer. Fig. 7 shows the side view of the connection module which has inside a high voltage high frequency filament transformer and will be connected to the klystron by a tube socket and to the HV transformer by a HV cable. All of these three variants are now in the development. In the autumn of 2007 we expect that our test stand will be ready for the test of the first horizontal MBK.

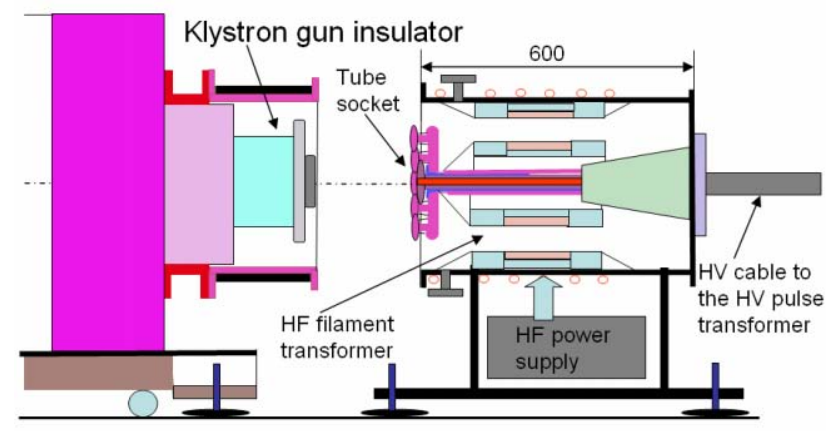

Figure 7: Connection between horizontal MBK and HV pulse transformer, inside of the connection module there are a HF filament transformer, $\mathrm{HV}$ feedthrough and tube socket.

\section{SUMMARY}

Today we can receive from the industry the vertical Lband 10MW MBKs which fully meet the specification of European XFEL project. Three companies have started the development of the horizontal version of MBK. During 2007-2008 we expect delivery first three horizontal tubes to DESY.

\section{REFERENCES}

[1] S. Choroba, "The TESLA RF System", Proc. of $6^{\text {th }}$ Workshop on High Energy Density and High Power RF, Berkeley Springs, June 2003, Vol. 691, p. 1-14.

[2] T. Grevsmuhl, S. Choroba, et al., "The RF-Station interlock For The European X-RAY”, LINAC'04, Lubeck, Germany, p.718..

[3] A. Yano, S. Miyake, S. Kazakov, et al., "The Toshiba E3736 Multi-Beam-Klystron”, LINAC'04, Lubeck, Germany, p.706..

[4] A. Beunas, G. Faillon, "10MW/1.5ms,L band multi beam klystron", Proc. Conf. Displays and Vacuum Electronics, Garmisch-Paterkirchen, Germany, April 29-30, 1998.

[5] V, Vogel, S. Matsumoto, "Detection of X-ray Due to Gun Arcing of High power Klystron", Proc. Of $1^{\text {st }}$ Annual Meeting of Particle Accelerator Society in Japan, Funabashi, Japan, pp.269-271, 2004.

[6] V. Vogel, S. Choroba, "Status of Multi-Beam Klystrons", Proc., 51th ILC DESY General Project Meeting. http://ilcagenda.cern.ch/categoryDisplay. py?categId=16 